\title{
Nutritional quality evaluation of different varieties of pomegranate under climatic conditions of Faisalabad
}

\author{
Naseem Akhtar *, Hafsa Zafar, Nisar Ahmad, Khalid Hussain
}

Biochemistry Section, Post-Harvest Research Centre, Ayub Agricultural Research Institute, Faisalabad, Pakistan

\section{Article Info}

Received : 10.10 .2018

Accepted : 09.04.2019

\begin{abstract}
The nutritional value of different pomegranate verities was determined in the laboratory of Biochemistry, Ayub Agricultural Research Institute (AARI), Faisalabad Pakistan to study the effectiveness of pomegranate juice as health responsive. The results showed that tested pomegranate varieties contained peels and seed percentage range from 34-40\% and $28-39 \%$ respectively. Juice contained a much higher remarkable content of total soluble solids ranged from (15-19\%), reducing sugar (10 to $14 \%$ ), non-reducing sugars (2.8 to $5 \%$ ), total invert sugars (13.8 to $18 \%)$, Vitamin-C (10.5 to $12.6 \mathrm{mg} / 100 \mathrm{~mL}$ ) and acidity (0.9 to $1.7 \%)$. Total phenols and antioxidants were higher in Sultan $(1101 \mu \mathrm{g}$ GAE $\mathrm{L}^{-1}$ (gallic acid equivalants) and 41.5\% DPPH (2,2-diphenyl-1-picrylhydrazyl) inhibition

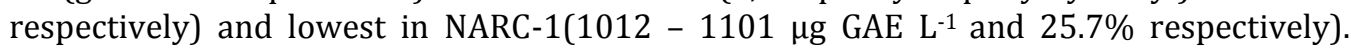
Therefore, the current results suggest that nutritional status of pomegranate variety, Sultan was better than Turnab Ghulabi, NARC-1, NARC-2 and Kandhari. It can be directed to incorporate Sultan (pomegranate) fruit juice for better nutritional status.
\end{abstract}

Keywords: Antioxidants, phenols, physico-chemical properties, pomegranate.

(C) 2019 Federation of Eurasian Soil Science Societies. All rights reserved

\section{Introduction}

Pomegranate juice is the best source of antioxidants among all the fruit juices (Seeram et al., 2008). It contains vitamin $\mathrm{C}$ and Flavonoid (plant based antioxidants) which help to reduce the risk of heart diseases and some kind of cancer. It also contains minerals. Prevention and treatments of diseases on the part of consumers, researchers and the food industry by using food products has become widely accepted (ViudaMartos et al., 2010 a,b). Functional foods find primary importance due to their role in physiological benefits and disease prevention or slow the progress of chronic diseases. Pomegranate is a functional food as it has multi functions relating to medicinal and nutritional benefits (Rowayshed et al., 2013).

It has great importance in human diet because of having several groups of substances, useful in disease risk reduction (Jaiswal et al., 2010). The pomegranate (Punica granatum) is a nutrient rich food source having phytochemical compounds. Phytochemical have been identified from various parts of the pomegranate tree and from pomegranate fruit: peel, juice and seeds. Pomegranates are prevalently consumed as fresh fruit, juice, beverages, jams, jellies and extracts. It is also used as botanical ingredients in herbal medicines and dietary supplements (Elfalleh et al., 2011). Bioactive compounds are preferably present in pomegranate and have been used in herbal medicine from ancient times. Many parts of pomegranate fruit possess colossal antioxidant activity. Its juice has high antioxidant activity and effectively prevents many diseases, such as atherosclerosis, low-density lipoprotein oxidation, prostate cancer, platelet aggregation and various cardiovascular diseases (Adhami and Mukhtar, 2006).

All parts of pomegranate (Punica granatum L.), leaf, seed, juice, husk and peel grab attention to study their role in bioactivities (Lansky and Newman, 2007). Pomegranate seed contains a range of nutraceutical components such as sterols, $\gamma$-tocopherol, punicic acid and hydroxyl benzoic acids (Liu et al., 2009).

\footnotetext{
${ }^{*}$ Corresponding author.

Biochemistry Section, Post-Harvest Research Centre, Ayub Agricultural Research Institute, Faisalabad, Pakistan

Tel.: +923427606376

e-ISSN: 2147-4249

E-mail address: nasimsajjad235@gmail.com DOI: $10.18393 /$ ejss.552543
} 
Pomegranate seed is more valuable in food industries as it has great role in by-product of juice and concentrates production plants, valuable pharmaceutical and nutritional compounds (unsaturated fatty acids and phenolic compounds) in the seed and their antioxidant properties (Rowayshed et al., 2013). The objective of this study was to assess and compare the quality of various varieties of pomegranate under climatic conditions of Faisalabad Pakistan.

\section{Material and Methods}

The present study was conducted at Biochemistry Section, Ayub Agricultural Research Institute, Faisalabad in collaboration with Horticultural Research institute AARI, Faisalabad Pakistan during the month of August and September in year 2017-18 to assess the nutritional quality of different varieties of pomegranate under climatic conditions of Faisalabad. Metrological data during the months of August and September 2017 and 2018 is given in Table 1. Soil properties of the field area of Horticulture Research Institute are given in Table 2. Five pomegranate varieties i.e. Tarnab Gulabi, NARC-1, NARC-2, Sultan and Kandhari were collected from Horticultural Research Institute AARI Faisalabad at maturity. The fruits were washed with water and wiped to completely dry. Fruits were peeled manually, separating the seeds and juice was extracted mechanically by using mechanical juicer blender. Then the juice was filtered through muslin cloth. The juices were immediately stored at $4^{\circ} \mathrm{C}$ in the refrigerator for further analysis. Data was collected about peel and seed percentage and juice was analyzed for TSS, acidity, vitamin C, reducing sugar, non-reducing sugar, total invert sugar, total antioxidant and total phenols.

Table 1. Summarized Meteorological data for the growing season 2017-18 (Source: Meteorological data, recorded at the observatory of Plant Physiology Section Agronomic Research Institute, Faisalabad Pakistan)

\begin{tabular}{lcccc}
\hline Parameters & August 2017 & September 2017 & August 2018 & September 2018 \\
\hline Max. Temperature ${ }^{\circ} \mathrm{C}$ & & & & \\
\hline Mean max. Temp. & 37.4 & 36.9 & 36.5 & 37.7 \\
Highest Max. Temp & 40.0 & 39.5 & 39.5 & 40.5 \\
Lowest Max. Temp. & 30.6 & 32.5 & 30.0 & 34.5 \\
\hline Minimum Temperature ${ }^{\circ} \mathrm{C}$ & & & & \\
\hline Mean Min. Temp. & 26.9 & 23.4 & 24.6 & 28.1 \\
Highest Min. Temp & 29.6 & 26.7 & 28.0 & 30.3 \\
Lowest Min. Temp. & 21.0 & 20.0 & 19.0 & \\
\hline Relative Humidity (\%) & & & & 73.5 \\
\hline Mean Rela Humi 8 am & 73.1 & 69.9 & 53.5 & 56.7 \\
Mean Rela Humi 8 am & 54.9 & 51.2 & 38.0 & 44.0 \\
Lowest Rela Humi & 41.0 & 33.0 & 87.0 & 92.0 \\
Highest Rela Humi & 92.0 & 91.0 & & \\
\hline Sun Shine (Hours) & & & $8-13$ & $7-54$ \\
\hline Mean daily sunshine (hrs) & $8-15$ & $9-05$ & 85.4 & 15.2 \\
Total Sunshine (hrs) & $255-40$ & $272-20$ & 2.0 & 1.0 \\
\hline Rain fall (mm) & 65.7 & 19.0 & & \\
\hline Cloudy Nights & 5.0 & 3.0 & & \\
\hline
\end{tabular}

\section{Titratable Acidity, pH, total soluble solids content}

Titratable acidity (TA) was determined by titration to $\mathrm{pH} 8.1$ with $0.1 \mathrm{M} \mathrm{NaOH}$ solution and expressed as g of citric acid per $100 \mathrm{~g}$ of juice (AOAC, 2005). The pH and soluble solids content of the juice were measured immediately after extraction using $\mathrm{pH}$ meter and digital refractometer, respectively. The $\mathrm{pH}$ meter was calibrated with standards having $\mathrm{pH} 4$ and 9 . The refractometer was calibrated using distilled water and measurement was done with the temperature compensated mode. All measurements were made in triplicate and average results were reported. The total sugars were estimated according to the method described by Ranganna (2001). Ascorbic acid contents (g/100 mL juice) of samples were determined according to the titration method using 2, 6-dichlorophenol indophenol as was reported by AOAC (AOAC, 2005).

\section{Total phenols and total antioxidants}

Pomegranate juice was extracted with mixture of methanol, acetone and $\mathrm{HCl}$. Extraction mixture was prepared with methanol, acetone and $\mathrm{HCl}$ in the ratio of 90:8:2 respectively. Extraction was carried out by taking $1 \mathrm{~mL}$ of pomegranate juice vertexed with $5 \mathrm{~mL}$ of extraction mixture and centrifuged at $400 \mathrm{rpm}$ for 5 minutes. Took the supernatant and stored for phenols and antioxidant determination. The measurement of the antioxidants was carried out as radical scavenging activity of DPPH (2,2-diphenyl-1-picrylhydrazyl) according to method describe by Brand-Williams et al. (1995) and Sánchez-Moreno et al. (1998). DPPH was 
diluted methanol and $0.004 \%$ DPPH methanol solution was prepared. Took $0.5 \mathrm{~mL}$ of supernatant and mixed with $3 \mathrm{~mL} 0.004 \%$ DPPH solution. The mixtures were incubated in the dark for $30 \mathrm{~min}$. Absorbance of the resulting solution was measured at $517 \mathrm{~nm}$ by a UV-Visible spectrophotometer. The reading with $0.004 \%$ $\mathrm{DPPH}$ was used as blank $\left(\mathrm{A}_{0}\right)$ along with samples reading as ' $A$ '. The results were expressed as the percentage of inhibition of the DPPH. Total antioxidants are determined by following equation:

Total antioxidant $[\%$ of DPPH reducing activity $]=\left[\left(\mathrm{A}_{0}-\mathrm{A}\right) / \mathrm{A}_{0}\right] \times 100$

Total phenolic contents were determined using a Folin-Ciocaltau colometric method and expressing the result as gallic acid equivalents (GAE). Supernatant sample $(0.2 \mathrm{ml})$ was mixed with $0.1 \mathrm{ml}$ of ten-fold diluted Folin-Ciocalteu reagents and $0.8 \mathrm{ml}$ of $7.5 \%$ sodium carbonate solution. Gallic acid was used as standards and results were expressed as gallic acid equivalents (GAE) per $100 \mathrm{~mL}$. After standing the prepared samples for $30 \mathrm{~min}$ at room temperature, the absorbance was measured at $765 \mathrm{~nm}$ using spectrophotometer (Singleton and Rossi, 1999). Graph was prepared with standard values and calculated the total phenols as Gallic acid equalants

Table 2. Physico-chemical prperties of the soils

\begin{tabular}{lc} 
Sand, \% & 50.3 \\
Silt, \% & 27.7 \\
Clay, \% & 22.0 \\
Texture type & Sandy clay loam \\
Saturation percentage, \% & 39.0 \\
pH & 7.9 \\
EC, dSm -1 & 1.4 \\
Organic matter, \% & 0.76 \\
Nitrogen, \% & 0.030 \\
Available phosphorus (P), $\mathrm{mg} \mathrm{kg}^{-1}$ & 7.2 \\
Extractable potassium (K), $\mathrm{mg} \mathrm{kg}^{-1}$ & 120 \\
\hline
\end{tabular}

\section{Statistical analysis}

Data was arranged over the year and varieties were compared statistically. Means and standard deviations were calculated for three independent determinations for each variable. Correlation matrix was done using MS Excel 2003 version. Standard errors of means of the data were computed (Steel et al., 1997) whilst means were compared by Duncan's Multiple Range Test (Duncan, 1955).

\section{Results}

The results regarding physical and nutritional parameters of pomegranate are given in Table 3, 4 and 5 respectively. Juice percentage in different pomegranate varieties ranged from 22.7 to $33.1 \%$. Maximum juice percentage was recorded in NARC-1 (33.1\%) while minimum was recorded in Kandhari (22.7\%). TSS of pomegranate juice samples ranged from 15.6 to18.6\% as maximum TSS (18.6\%) was recorded in Sultan while minimum was recorded in NARC-2 and Kandhari (15.6\%). Maximum peel percentage was recorded in NARC-1 (42\%) while minimum peel was recorded in Sultan (35.1\%). Seed percentage in pomegranate samples ranged from 32.1 to $36 \%$. Ascorbic acid contents of juice of different pomegranate samples was found maximum in Kandhari and Tarnab Gulabi $(12.7 \mathrm{mg} / 100 \mathrm{~g})$ and minimum was recorded in NARC-2 $(10.6 \mathrm{mg} / 100 \mathrm{~g})$. Data regarding reducing sugar ranged from 10.4 to $12.1 \%$ such that maximum reducing sugar $(12 \%)$ was recorded in Sultan while minimum reducing sugar $(10.4 \%)$ was recorded in NARC-2. Regarding non reducing sugar, maximum was recorded in Sultan (5.7\%) which is statistically at par with Tarnab Gulabi (5.3\%) while minimum non-reducing sugar was present in NARC-I (3.6\%). Total invert sugar recorded in juice of pomegranate samples ranged from 14.4 to18.1\%. Similar trend was observed regarding total invert sugar having maximum in Sultan (18.1\%) while minimum total invert sugar (14.4\%) was recorded in NARC-1 and Kandhari.

Table 3. Comparison of physical parameters of different pomegranate varieties

\begin{tabular}{lccccc}
\hline Variety & Fruit wt, (g/fruit) & Juice (\%) & TSS (\%) & Peel (\%) & Seed (\%) \\
\hline TarnabGulabi & $147.7 \pm 3.1$ & $30.9 \pm 1.8$ & $16.9 \pm 0.50$ & $36.0 \pm 1.9$ & $33.1 \pm 1.7$ \\
NARC -1 & $235.0 \pm 2.6$ & $32.9 \pm 0.7$ & $15.4 \pm 0.26$ & $39.0 \pm 2.7$ & $27.7 \pm 2.5$ \\
NARC-2 & $213.4 \pm 23$ & $30.0 \pm 1.7$ & $15.2 \pm 0.74$ & $34.0 \pm 3.5$ & $35.9 \pm 3.8$ \\
Kandhari & $160.2 \pm 3.6$ & $20.6 \pm 2.8$ & $15.9 \pm 0.67$ & $40.0 \pm 1.3$ & $38.9 \pm 3.4$ \\
Sultan & $186.4 \pm 2.3$ & $32.4 \pm 1.6$ & $19.2 \pm 0.53$ & $36.0 \pm 2.4$ & $31.1 \pm 2.8$ \\
\hline
\end{tabular}

Total antioxidant and total phenols of different varieties of pomegranate are given in Table 5.The DPPH radical scavenging assay is commonly employed to evaluate the ability of antioxidant to scavenge free 
radicals. The degree of discoloration indicates the scavenging potentials of the antioxidant extract. In this study, the differences in antioxidant capacity among the pomegranate cultivars were statistically significant and the values ranged from 25.7 (NARC-1) to 41.5\% (Sultan). Total phenols were found higher in Sultan (1101 $\left.\mu \mathrm{g} \mathrm{GAE} \mathrm{L}^{-1}\right)$ followed by Kandhari $\left(1075 \mu \mathrm{g}\right.$ GAE $\left.\mathrm{L}^{-1}\right)$ while minimum was observed in NARC-1 (1012 $\mu \mathrm{g}$ GAE $\mathrm{L}^{-1}$ ).

Table 4. Comparison of nutritional quality parameters of pomegranate varieties

\begin{tabular}{lccccc}
\hline Variety & $\begin{array}{c}\text { Reducing sugar } \\
(\%)\end{array}$ & $\begin{array}{c}\text { Non-reducing } \\
\text { sugars (\%) }\end{array}$ & $\begin{array}{c}\text { Total invert } \\
\text { sugars (\%) }\end{array}$ & $\begin{array}{c}\text { Vitamin C } \\
(\mathrm{mg} / 100 \mathrm{~mL})\end{array}$ & Acidity (\%) \\
\hline Tarnab Gulabi & $10.6 \pm 0.38$ & $5.0 \pm 0.66$ & $15.9 \pm 0.66$ & $12.4 \pm 0.81$ & $1.6 \pm 0.018$ \\
NARC - 1 & $11.2 \pm 0.84$ & $2.8 \pm 0.95$ & $14.1 \pm 0.43$ & $12.0 \pm 0.48$ & $1.7 \pm 0.022$ \\
NARC-2 & $10.3 \pm 0.38$ & $3.4 \pm 0.58$ & $13.8 \pm 0.54$ & $10.5 \pm 0.82$ & $1.6 \pm 0.017$ \\
Kandhari & $11.4 \pm 0.94$ & $3.2 \pm 0.67$ & $14.7 \pm 0.39$ & $12.6 \pm 0.62$ & $1.2 \pm 0.019$ \\
Sultan & $14.2 \pm 1.90$ & $3.9 \pm 1.36$ & $18.3 \pm 0.59$ & $11.7 \pm 0.52$ & $0.9 \pm 0.192$ \\
\hline
\end{tabular}

Table 5. Comparison of antioxidants and total phenols of pomegranate varieties

\begin{tabular}{lcc}
\hline Variety & Antioxidant capacity (DPPH inhibition \%age) & Total Phenols $\left(\mu \mathrm{g} \mathrm{GAE} \mathrm{L}^{-1}\right)$ \\
\hline Tarnab Gulabi & $30.9 \pm 6.90$ & $1021 \pm 12.20$ \\
NARC -1 & $25.7 \pm 0.53$ & $1012 \pm 12.40$ \\
NARC-2 & $36.2 \pm 8.90$ & $1037 \pm 13.31$ \\
Kandhari & $39.4 \pm 7.30$ & $1075 \pm 12.71$ \\
Sultan & $41.5 \pm 8.20$ & $1101 \pm 13.35$ \\
\hline
\end{tabular}

\section{Discussion}

Among the fruit juices, pomegranate juice is considered as one of the superlative sources of antioxidants. Although it is not a rich source of well-known antioxidants such as vitamin C, however it contains plantbased antioxidants such as flavonoids (Elfalleh et al., 2011). These antioxidants may help to reduce the peril of cardiac disease and avoid some types of cancer (Afaq et al., 2005; Khan et al., 2007; Malik and Mukhtar, 2006). Pomegranate juice is also a good source of mineral (Opara et al., 2009; Melgarejo et al., 2011). TSS contents in pomegranate juice of Sultan was higher than other varieties and the obtained results are similar to those reported by Martinez et al. (2006) and Tehranifar et al. (2010).

The difference in fruit weight of different varieties is due to environmental conditions as explained previously by Zaouay et al. (2012) who determined that difference in fruit weight depended on the variety and environmental condition. The varieties, NARC-1 and Sultan with higher percentage of juice (32.9 and 32.4 respectively), could be more promising than other varieties because juice percentage is highly desirable property in the food processing and beverage industry (Rajasekar et al., 2012).

The differences among varieties were detected in $\mathrm{pH}$ and total acidity values might be due to the phenolic pattern of the juice obtained from different varieties of pomegranate seeds (Gil et al., 2000). Pomegranates, like most other fruits are impartially higher in natural sugar. The total sugars contents in different varieties of pomegranate are in line with those observed by Poyrazoglu et al. (2002) and Aviram et al. (2000). Results of Youssef et al. (2007) regarding vitamin C, supported the results of this study. The results depicted that the juice composition of pomegranate and its bioactive compounds depends on variety and maturity index as determined by Miguel et al. (2004). Antioxidants and total phenols content of the juices of five tested varieties varies considerably and similar to the results obtained by Faria and Calhau (2010). However all the varieties contained antioxidants which make them favourable for healthy consumption.

\section{Conclusion}

It was concluded that different varieties of pomegranate contained different values of Antioxidants, total phenols, total invert sugar, reducing sugar, $\mathrm{pH}$ and TSS. However, overall performance of pomegranate variety, Sultan regarding various quality parameters was found better.

\section{References}

Adhami, V.M., Mukhtar, H., 2006. Polyphenols from green tea and pomegtanate for prevention of prostate cancer. Free Radical Research 40(10): 1095-1104.

Afaq, F., Saleem, M., Krueger, C.G., Reed, J.D., Mukhtar, H., 2005. Anthocyanin- and hydrolysable tannin-rich pomegranate fruit extract modulates MAPK \& NF-kappa B pathways and inhibits skin tumorigenesis in CD-1 mice. International Journal of Cancer 113(3): 423-433.

AOAC., 2005. Association of Official Ananlytical Chemists. Official Methods of Analysis of the AOAC International, 18th edition Gaithersburg Marylad 20877- 2417, USA.

Aviram, M., Dornfeld, L., Rosenblat, M., Volkova, N., Kalplan, M., Coleman, R., Hayek, T., Presser, D., Fuhrman, B., 2000. Pomegranate juice consumption reduces oxidative stress, atherogenic modifications to LDL and platelet 
aggregation, Studies in humans and in atheroscierotic E- deficient mice. American Journal of Clinical Nutrition 71(5): 1062-1076.

Brand-Williams, W., Cuvelier, M.E., Berset, C. 1995. Use of a free radical method to evaluate antioxidant activity. $L W T$ Food Science and Technology 28(1): 25-30.

Duncan, D.B., 1955. Multiple Range and Multiple FTest. Biometrics 11: 1-42.

Elfalleh, W., Tlili, N., Nasri, N., Yahia, Y., Hannachi, H., Chaira, N., Ying, M., Ferchichi, A., 2011. Antioxidant capacities of phenolic compounds and tocopherols from Tunisian pomegranate (Punica granatum) fruits. Journal of Food Sciences 76(5): 707-713.

Faria, A., Calhau, C., 2010. Pomegranate in Human Health: An Overview. In: Bioactive Foods in Promoting Health - Fruits and Vegetables. Watson, R.R., Preedy, V.R. (Eds.). Academic Press. pp. 551-563.

Gil, M.I., Tomas-Barberan, F.A., Hess-Pierce, B., Holcroft, D.M., Kader, A.A., 2000. Antioxidant activity of pomegranate juice and its relationship with phenolic Composition and processing. Journal of Agricultural and Food Chemistry 48(10): 4581-4589.

Jaiswal, V., DerMarderosian, A., Porter, J.R., 2010. Anthocyanins and polyphenoloxidase from dried arils of pomegranate (Punica granatum L). Food Chemistry 118(1): 11-16.

Khan, N., Afaq, F., Kweon, M.H., Kim, K., Mukhtar, H., 2007. Oral consumption of pomegranate fruit extract inhibits growth and progression of primary lung tumors in mice. Cancer Research 67(7): 3475-3482.

Lansky, E.P., Newman, R.A., 2007. Punica granatum (pomegranate) and its potential for prevention and treatment of inflammation and cancer. Journal of Ethnopharmacology 109(2): 177-206.

Liu, G., Xu, X., Hao, Q., Gao, Y., 2009. Supercritical CO2 extraction optimization of pomegranate (Punica granatum L.) seed oil using response surface methodology. LWT Food Science Technology 42(9): 1491-1495.

Malik, A., Mukhtar, H., 2006. Prostate cancer prevention through pomegranate fruit. Cell Cycle 5(4): 371-373.

Martinez, J.J., Melgarejo, P., Hernandez, F., Salazzar, D.M., Marinez, R., 2006. Seed characterisation of five new pomegranate (Punica granatum L.) varieties. Scientia Horticulturae 110(8): 241-246.

Melgarejo, P., Martínez, R., Hernández, F., Martínez, J.J., Legua, P., 2011. Anthocyanin content and colour development of pomegranate jam. Food Production and Processing 89(4): 477-481.

Miguel, G., Fontes, C., Antunes, D., Neves, A., Martins, D., 2004. Anthocyanin concentration of “Assaria” pomegranate fruits during different cold storage conditions. Journal of Biomedical and Biotechnology 5: 338-342.

Opara, LU., Al-Ani, M.R., Al-Shuaibi, Y.S., 2009. Physico-chemical properties, vitamin C content and antimicrobial properties of pomegranate fruit (Punica granatum L.). Food and Bioprocess Technology 2(3): 315-321.

Poyrazoglu, E., Gokmen, V., Artik, N., 2002. Organic acids and phenolic compounds in pomegranates (Punica granatum L.) grown in Turkey. Journal of Food Composition and Analysis 15(5): 567-575.

Rajasekar, D, Akoh, C.C., Martino, K.G., MacLean, D.D., 2012. Physico-chemical characteristics of juice extracted by blender and mechanical press from pomegranate cultivars grown in Georgia. Food Chemistry 133(4): 1383-1393.

Ranganna, S., 2001. Sugar Estimation. In: Handbook of analysis and quality control for fruit and vegetable products. Ranganna, S. (Ed.). Tata McGraw-Hill publications, New Delhi, India. pp. 12-17.

Rowayshed, G., Salama, A., Abul-Fadl, M., Akila-Hamza, S., Emad, A., Mohamed., 2013. Nutritional and chemical evaluation for pomegranate (Punica granatum L.) fruit peel and seeds powders by products. Middle East Journal of Appliied Science 3(4): 169-179.

Sánchez-Moreno, C., Larrauri, J.A., Saura-Calixto, F., 1998. A procedure to measure the antiradical efficiency of polyphenols. Journal of Science Food and Agriculture 76(2): 270-276.

Seeram, N.P., Aviram, M., Zhang, Y., Henning, S.M., Feng, L., Dreher, M., Heber, D., 2008. Comparison of antioxidant potency of commonly consumed polyphenol-richbeverages in the United States. Journal of Agriculture and Food Chemistry 56(4): 1415-1422.

Singleton, V.L., Orthofer, R., Lamuela-Raventos, R.M., 1999. Analysis of total phenols and other oxidation substrates and antioxidants by means of folin-ciocalteu reagent. Methods in Enzymology 299: 152-178.

Steel, R.G.D., Torrie, J.H., Dicky, D.A., 1997. Principles and procedures of statistics- A biometrical approach. 3rd Edition, McGraw-Hill Book International Co., Singapore. 666p.

Tehranifar, A., Zarei, M., Nemati, Z., Esfandiyari, B., Vazifeshenas, M.R., 2010. Investigation of physico-chemical properties and antioxidant activity of twenty Iranian pomegranate (Punica granatum L.) cultivars. Scientia Horticulturae 126(2): 180-185.

Viuda-Martos, M., Fernández-López, J., Pérez-Álvarez, J.A., 2010a. Pomegranate and its many functional components as related to human health: A review. Comparative Reviews in Food Science and Food Safety 9(6): 635-654.

Viuda-Martos, M., López-Marcos, M.C., Fernández-López, J., Sendra, E., López-Vargas, J.H., Pérez-Álvarez, J.A., 2010b. Role of fiber in cardiovascular diseases. A review. Comparative Reviews in Food Science and Food Safety 9: 240258.

Youssef, M.K., El-Dengawy, R.A.H., Khalifa, A.H.A., Abd El-Rahman, M.A.M., 2007. Physico-Chemical quality attributes of fresh and treated juice of some Egyptian pomegranate varieties. The 8th Conference and Exhibition on Food Industries Between Quality and Competitiveness 28-30 August 2007. Alex Egypt.

Zaouay, F., Mena, P., Garcia-Viguera, C., Mars, M., 2012. Antioxidant activity and physico- chemical properties of Tunisian grown pomegranate (Punica granatum L.). Industrial Crops and Product 40: 81-89. 